\title{
SARS-CoV-2 seroprevalence in health care workers from 10 hospitals in Quebec, Canada: a cross-sectional study
}

\author{
Nicholas Brousseau MD MSc, Laurianne Morin BSc, Manale Ouakki PhD, Patrice Savard MD MSc, \\ Caroline Quach MD MSc, Yves Longtin MD, Matthew P. Cheng MD, Alex Carignan MD MSc, Simon F. Dufresne MD, \\ Jean-Michel Leduc MD, Christian Lavallée MD, Nicolas Gauthier PhD, Julie Bestman-Smith MD PhD, \\ Maria-Jesus Arrieta MD, Magued Ishak MD, Simon Lévesque PhD, Philippe Martin MD, Gaston De Serres MD PhD
}

Cite as: CMAJ 2021 December 13;193:E1868-77. doi: 10.1503/cmaj.202783

\section{Abstract \\ Background: The COVID-19 pandemic has disproportionately affected health care workers. We sought to estimate SARS-CoV-2 seroprevalence among hospi- tal health care workers in Quebec, Can- ada, after the first wave of the pandemic and to explore factors associated with SARS-CoV-2 seropositivity.}

Methods: Between July 6 and Sept. 24, 2020 , we enrolled health care workers from 10 hospitals, including 8 from a region with a high incidence of COVID-19 (the Montréal area) and 2 from low-incidence regions of Quebec. Eligible health care workers were physicians, nurses, orderlies and cleaning staff working in 4 types of care units (emergency department, intensive care unit, COVID-19 inpatient unit and non-COVID-19 inpatient unit). Participants completed a questionnaire and underwent SARS-CoV-2 serology testing. We identified factors independently associated with higher seroprevalence.

Results: Among 2056 enrolled health care workers, 241 (11.7\%) had positive SARS-CoV-2 serology. Of these, 171 (71.0\%) had been previously diagnosed with COVID-19. Seroprevalence varied among hospitals, from $2.4 \%$ to $3.7 \%$ in low-incidence regions to $17.9 \%$ to $32.0 \%$ in hospitals with outbreaks involving 5 or more health care workers. Higher seroprevalence was associated with working in a hospital where outbreaks occurred (adjusted prevalence ratio 4.16, 95\% confidence interval $[\mathrm{Cl}] 2.63-$
6.57), being a nurse or nursing assistant (adjusted prevalence ratio $1.34,95 \% \mathrm{Cl}$ 1.03-1.74) or an orderly (adjusted prevalence ratio $1.49,95 \% \mathrm{Cl} 1.12-1.97$ ), and Black or Hispanic ethnicity (adjusted prevalence ratio $1.41,95 \% \mathrm{Cl} 1.13-1.76$ ). Lower seroprevalence was associated with working in the intensive care unit (adjusted prevalence ratio $0.47,95 \% \mathrm{Cl}$ $0.30-0.71$ ) or the emergency department (adjusted prevalence ratio $0.61,95 \% \mathrm{Cl}$ 0.39-0.98).

Interpretation: Health care workers in Quebec hospitals were at high risk of SARS-CoV-2 infection, particularly in outbreak settings. More work is needed to better understand SARS-CoV-2 transmission dynamics in health care settings.
$\mathrm{T}$ he COVID-19 pandemic has disproportionately affected health care workers. In France, Spain, Italy, Germany and the United States, at least $10 \%$ of cases reported in spring 2020 were in health care workers. ${ }^{1}$ In Quebec, $25 \%$ (14177 of 56565) of all cases declared during the first wave of the pandemic, from March to July 2020, were in health care workers, ${ }^{2}$ about one-third of whom were working in acute care hospitals. ${ }^{1}$ The Montréal area was the most affected region in Quebec and Canada during the first wave, reaching a COVID-19 incidence rate of 1336 per 100000 population. ${ }^{2}$

The number of COVID-19 cases reported among health care workers underestimated the number of those infected with SARSCoV-2 during that period, given limited testing leading to undiag- nosed asymptomatic or paucisymptomatic infections. ${ }^{3}$ Seroprevalence studies are an important tool to determine the proportion of people infected with SARS-CoV-2, both in the general population and among health care workers. ${ }^{4}$ After the first wave in Quebec, SARS-CoV-2 seroprevalence in adults aged 18-69 years was found to be low (3.1\% in Montréal and $1.3 \%$ in less affected regions), but this proportion could be much higher among health care workers who had to work despite the general shutdown of social and economic activities, especially if they were exposed to major outbreaks. ${ }^{5}$

Only 2 other Canadian studies provide SARS-CoV-2 seroprevalence estimates among health care workers, and both studies were from a single centre. ${ }^{6,7}$ Outside Canada, most seroprevalence studies 
among health care workers include a single site and do not provide a representative estimate for a defined region. ${ }^{8}$ Several studies have reported a higher seroprevalence among health care workers from units treating patients with COVID-19 (COVID-19 units) compared with other units (non-COVID-19 units), emergency departments or intensive care units. ${ }^{9,10}$ Other studies have not identified such associations. ${ }^{11,12}$ In this study, we aimed to assess the seroprevalence of SARS-CoV-2 antibody among hospital health care workers from a variety of settings after the first pandemic wave in Quebec, and to explore factors associated with SARS-CoV-2 seropositivity.

\section{Methods}

\section{Population and design}

We conducted a cross-sectional seroprevalence study of hospital health care workers between July 6 and Sept. 24, 2020. Targeted health care workers included physicians, nurses, nursing assistants, orderlies and cleaning staff. Included health care workers had to be older than 18 years, be assigned to the unit for the entire shift during which recruitment occurred and provide direct care to patients (or, for cleaning staff, be exposed to their direct environment). We did not exclude people who had a previous positive SARS-CoV-2 test result.

\section{Recruitment and data collection}

We recruited health care workers from 10 acute care hospitals receiving patients with COVID-19 in Quebec (Appendix 1, Supplementary Table 1, available at www.cmaj.ca/lookup/doi/10.1503/ cmaj.202783/tab-related-content). Eight hospitals are located in Montréal, a region that was more affected (1336 cases per 100000 people) than the provincial average (662 cases per 100000 people) during the first wave. ${ }^{2}$ The other 2 hospitals are located in the Eastern Townships (200 cases per 100000 people) and CapitaleNationale (249 cases per 100000 people) regions.

We recruited participants from 4 types of units, namely emergency departments, intensive care units, COVID-19 inpatient units, and non-COVID-19 inpatient units, targeting 50 health care workers per unit per hospital. We wanted to document seroprevalence in a variety of settings, including some that provided care to patients with COVID-19. When the number of health care workers was large (mostly in emergency departments), hospital sites were authorized to select a limited number of workdays to reduce the number of health care workers eligible for inclusion. A few COVID-19 and nonCOVID-19 units did not have enough health care workers to reach the target and we expanded recruitment to an additional unit with similar patient characteristics and work environment. Personal protective equipment was readily available in all units.

For each unit, we obtained a list of health care workers. We invited all health care workers by email, and sent nonresponders 3 reminders, 48 hours apart. We recruited the first consecutive health care workers that were interested in participating (up to 75 health care workers) when the message was sent out.

Participating health care workers completed an online questionnaire containing 18 questions about sociodemographic data, health status and work-related environment, and a question about the occurrence of any symptoms congruent with COVID-19 since Mar. 1, 2020. We asked participants to self-identify their ethnicity, as ethnicity has been associated with seroprevalence. ${ }^{13}$ The questionnaire was available in English and French. Eligible health care workers also provided serology samples. Participants had to complete both the questionnaire and serology to be included.

Each hospital site investigator also completed a short questionnaire, mainly to describe outbreaks that occurred in participating units. We classified participants as working in a hospital where outbreaks occurred if at least 1 participating unit at their hospital had an outbreak involving 5 or more health care workers as, in such hospitals, outbreaks were often documented or suspected in most or all participating units.

We validated all participant-reported prior COVID-19 illnesses using a provincial database on SARS-CoV-2 polymerase chain reaction (PCR) test results. ${ }^{2}$ To determine the timing of blood samples in relation to COVID-19 activity in Quebec, we extracted data on the weekly number of COVID-19 cases from the Institut national de santé publique du Québec website. ${ }^{2}$

\section{Serological tests}

Serological testing to detect 2 subunits (S1/S2) of the SARS-CoV-2 spike protein used an indirect chemiluminescence immunoassay with anti-S1/S2 immunoglobulin (Ig) G, (LiaisonXL analyzer and the LIAISON SARS-CoV-2 S1/S2 IgG test from DiaSorin in accordance with the manufacturer's instructions. Using $20 \mu \mathrm{L}$ of the sample, the analyzer automatically calculated antibody concentrations, expressed as arbitrary units $(\mathrm{AU} / \mathrm{mL})$, and graded the results. The limit of detection was $3.8 \mathrm{AU} / \mathrm{mL}$ and results of $15 \mathrm{AU} / \mathrm{mL}$ or greater were considered positive. A Quebec-based study reported a sensitivity of $82 \%-88 \%$ ( $\geq 35$ days post-infection) and a specificity of $100 \%$ for this immunoassay. ${ }^{14} \mathrm{~A}$ subset of sera was analyzed using a second method, the NADAL COVID-19 IgG/ IgM test, which detects the anti-S1 receptor binding domain (Nal von Minden, Appendix 1).

\section{Statistical analysis}

We tried to recruit 200 health care workers per hospital and 50 health care workers per unit to achieve a precision of $\pm 2 \%$ at the hospital level and $\pm 4 \%$ at the unit level for the $95 \%$ confidence interval $(\mathrm{Cl})$. We assumed a $20 \%$ seroprevalence in the 8 Montréal hospitals ( $n_{\text {hospital }}=1600,95 \% \mathrm{Cl} 18 \%-22 \% ; n_{\text {unit }}=400,95 \% \mathrm{Cl} 16 \%-$ $24 \%$ ) and a $5 \%$ seroprevalence in the 2 hospitals in low-incidence regions ( $n_{\text {hospital }}=400,95 \% \mathrm{Cl} 3 \%-7 \% ; n_{\text {unit }}=100,95 \% \mathrm{Cl} 1 \%-9 \%$ ).

We estimated seroprevalence for each hospital and compared it according to various participant characteristics. We compared proportions using the $\chi^{2}$ or Fisher test, as appropriate. Univariate analyses identified variables associated with seropositivity that we included in the multivariate analyses. We used log-binomial generalized estimating equation (GEE) regression, which accounted for clustering within units and hospitals, ${ }^{15}$ to identify factors independently associated with seropositivity, evaluated with adjusted prevalence ratios. We assessed collinearity in the final model. We also calculated assay sensitivity (the proportion of participants with positive serology among participants with PCR-confirmed infection). We performed all statistical analyses with SAS 9.4 software. We set the significance level at 5\% and all tests were 2-sided. 


\section{Ethics approval}

This study was approved by the CHU de Québec-Université Laval ethics committee.

\section{Results}

We invited 4409 health care workers to participate (Figure 1). Of these, 2521 (57.2\%) signed the consent form, 2223 (50.4\%) were eligible to participate, and 2056 (46.6\%) had a blood sample drawn

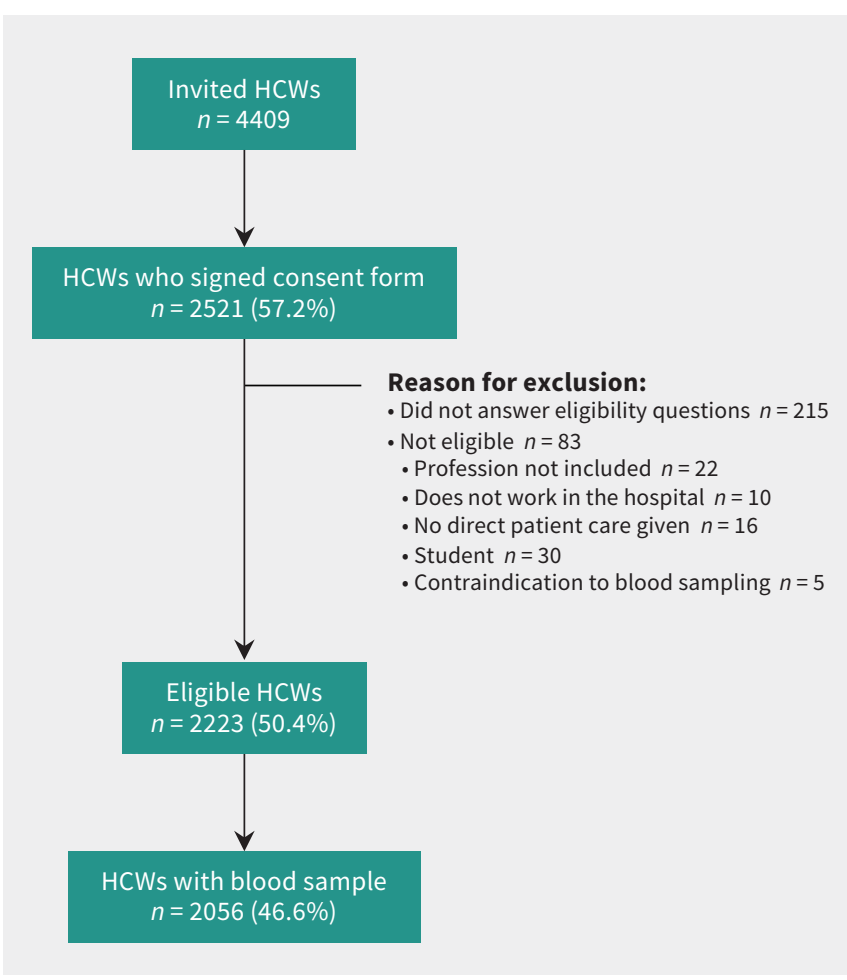

Figure 1: Study flow chart. Note: HCW = health care worker. and were included in the analyses. The participation rate among units varied from $43.1 \%$ to $49.2 \%$. The participation rate was highest among physicians (77.2\%), and lower for nurses (44.0\%), nursing assistants (36.6\%), cleaning staff (46.7\%) and orderlies (31.0\%).

Blood samples were drawn between July 6 and Sept. 24, 2020, between the first and second waves of the pandemic, when COVID-19 activity was low in Quebec (Figure 2). No outbreaks of COVID-19 were noted on targeted units during the study period.

\section{Health care workers}

In total, 1630 (79.3\%) of 2056 participants worked in a hospital from a high-incidence region and 426 (20.7\%) in a hospital from lowincidence regions (Table 1). Participants worked mainly in emergency departments $(28.2 \%)$, followed by intensive care units (22.9\%), COVID-19 units (21.2\%) and non-COVID-19 units (21.3\%). Most were nurses (57.8\%), between 30 and 49 years old (57.9\%), women $(76.1 \%)$, born in Canada (75.3\%) and white (77.6\%). Just over one-third of participants reported having had symptoms congruent with COVID-19 after Mar. 1, 2020 (37.4\%), and about half had had at least 1 PCR test (54.6\%). Most had worked more than 3 days per week in a COVID-19 unit after Mar. 1, 2020 (60.0\%), but a lower proportion had worked occasionally or regularly on a unit during a COVID-19 outbreak (41.0\%) or had been removed from work after close contact with a confirmed case (13.9\%; Table 1).

\section{Seroprevalence}

A total of 241 (11.7\%) of 2056 health care workers had positive serology. The seroprevalence was lower in low-incidence regions $(3.1 \%, 95 \% \mathrm{Cl} 1.8 \%-5.4 \%)$ than in the high-incidence region (14.0\%, 95\% Cl 12.3\%-15.8\%; Figure 3). In the high-incidence region, 4 hospitals had outbreaks in 1 or more targeted units that involved 5 or more health care workers. Seroprevalence ranged from $17.9 \%$ to $32.0 \%$ (mean $23.6 \%, 95 \% \mathrm{Cl} 20.6 \%-26.7 \%$ ) in hospitals with outbreaks of COVID-19 compared with $4.7 \%$ to $7.4 \%$ (mean $6.5 \%, 95 \%$ $\mathrm{Cl} 5.0 \%-8.4 \%)$ in the 4 hospitals without outbreaks.

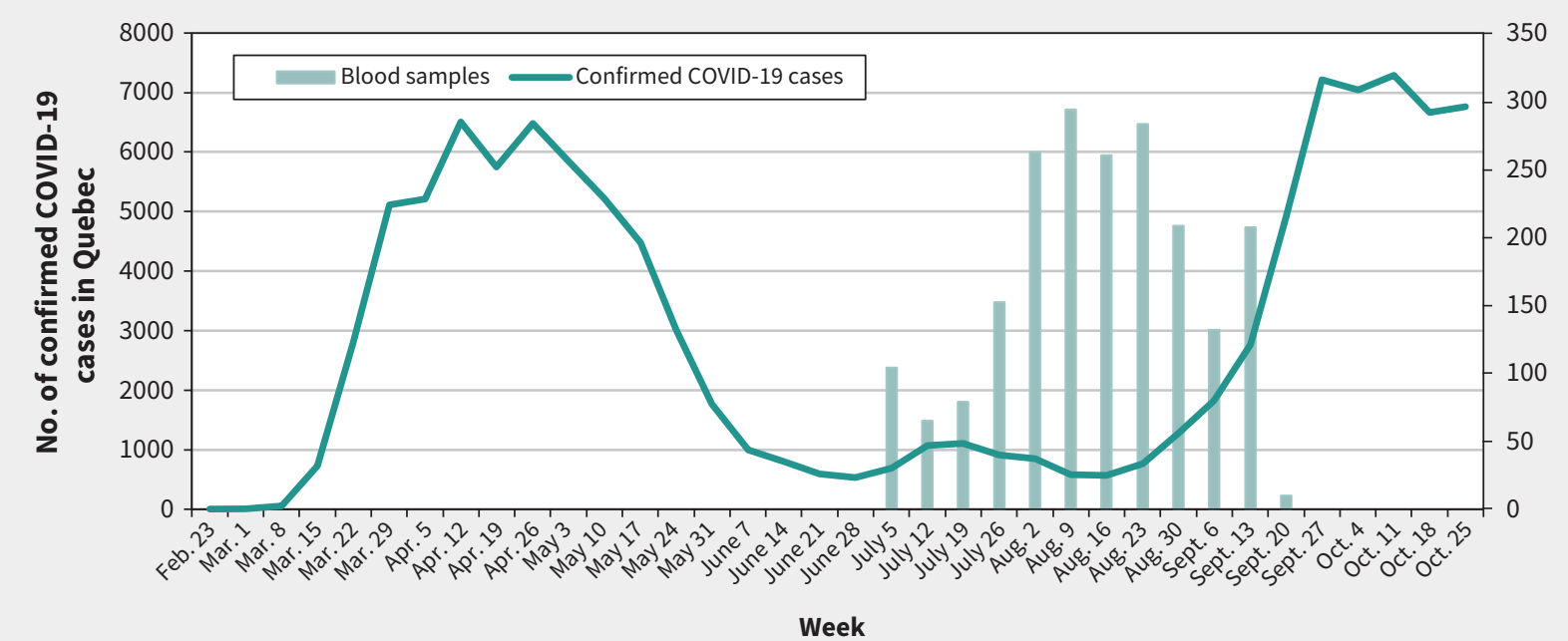

Figure 2: Weekly number of confirmed COVID-19 cases in Quebec and blood samples collected in the present study. 
Table 1 (part 1 of 2): SARS-CoV-2 antibody seroprevalence by participant characteristics

\begin{tabular}{|c|c|c|c|c|c|}
\hline Characteristic & Category & $\begin{array}{c}\text { No. }(\%) \text { of } \\
\text { participants } \\
n=2056\end{array}$ & $\begin{array}{l}\text { No. (\%) of participants } \\
\text { with positive serology } \\
\qquad n=241\end{array}$ & Seroprevalence, $\%$ & $p$ value \\
\hline \multirow{2}{*}{$\begin{array}{l}\text { Regional incidence of } \\
\text { COVID-19*}\end{array}$} & High & $1630(79.3)$ & $228(94.6)$ & 14.0 & \multirow[t]{2}{*}{$<0.001$} \\
\hline & Low & $426(20.7)$ & $13(5.4)$ & 3.1 & \\
\hline \multirow{2}{*}{$\begin{array}{l}\text { Work in a hospital where } \\
\text { outbreaks occurred } t\end{array}$} & Yes & $789(38.4)$ & $179(74.3)$ & 22.7 & \multirow[t]{2}{*}{$<0.001$} \\
\hline & No & $1267(61.6)$ & $62(25.7)$ & 4.9 & \\
\hline \multirow[t]{4}{*}{ Recruitment unit } & Emergency department & $600(29.2)$ & $47(19.5)$ & 7.8 & \multirow[t]{4}{*}{$<0.001$} \\
\hline & Intensive care unit & $470(22.9)$ & $29(12.0)$ & 6.2 & \\
\hline & COVID-19 unit & $496(24.1)$ & $99(41.1)$ & 20.0 & \\
\hline & Non-COVID-19 unit & $490(23.8)$ & $66(27.4)$ & 13.5 & \\
\hline \multirow[t]{5}{*}{ Main work unit } & Emergency department & $580(28.2)$ & $46(19.1)$ & 7.9 & \multirow[t]{5}{*}{$<0.001$} \\
\hline & Intensive care unit & $469(22.8)$ & $29(12.0)$ & 6.2 & \\
\hline & COVID-19 unit & $436(21.2)$ & $101(42.0)$ & 23.2 & \\
\hline & Non-COVID-19 unit & $438(21.3)$ & $51(21.2)$ & 11.6 & \\
\hline & Other & $133(6.5)$ & $14(5.8)$ & 10.5 & \\
\hline \multirow[t]{5}{*}{ Age group, yr } & $18-29$ & $427(20.8)$ & $41(17.0)$ & 9.6 & \multirow[t]{5}{*}{0.6} \\
\hline & $30-39$ & $643(31.3)$ & $78(32.4)$ & 12.1 & \\
\hline & $40-49$ & $547(26.6)$ & $70(29.0)$ & 12.8 & \\
\hline & $50-59$ & $356(17.3)$ & $43(17.8)$ & 12.1 & \\
\hline & $\geq 60$ & $83(4.0)$ & $9(3.7)$ & 10.8 & \\
\hline \multirow[t]{5}{*}{ Occupation } & Physician & $432(21.0)$ & $31(12.9)$ & 7.2 & \multirow[t]{5}{*}{0.007} \\
\hline & Nurse & $1189(57.8)$ & $141(58.5)$ & 11.9 & \\
\hline & Nursing assistant & $132(6.4)$ & $22(9.1)$ & 16.7 & \\
\hline & Orderly & $201(9.8)$ & $36(14.9)$ & 17.9 & \\
\hline & Cleaning staff & $102(5.0)$ & $11(4.6)$ & 10.8 & \\
\hline \multirow[t]{3}{*}{ Sex } & Male & $489(23.8)$ & $51(21.2)$ & 10.4 & \multirow[t]{3}{*}{0.3} \\
\hline & Female & $1564(76.1)$ & $189(78.4)$ & 12.1 & \\
\hline & Missing§ & $3(0.1)$ & - & - & \\
\hline \multirow[t]{3}{*}{ Born in Canada } & Yes & $1548(75.3)$ & $154(63.9)$ & 9.9 & \multirow[t]{3}{*}{$<0.001$} \\
\hline & No & $503(24.5)$ & $86(35.7)$ & 17.1 & \\
\hline & Missing & $5(0.2)$ & - & - & \\
\hline \multirow[t]{4}{*}{ Ethnicity } & White & $1594(77.5)$ & $163(67.6)$ & 10.2 & \multirow[t]{4}{*}{$<0.001$} \\
\hline & Black & $140(6.8)$ & $31(12.9)$ & 22.1 & \\
\hline & Hispanic & $52(2.5)$ & $14(5.8)$ & 26.9 & \\
\hline & Other & $270(13.1)$ & $33(13.7)$ & 12.2 & \\
\hline \multirow[t]{6}{*}{ Household } & 1 adult, no child & $328(16.0)$ & $31(12.9)$ & 9.5 & \multirow[t]{6}{*}{0.009} \\
\hline & 2 adults, no child & $480(23.3)$ & $54(22.4)$ & 11.3 & \\
\hline & $\geq 3$ adults, no child & $234(11.4)$ & $35(14.5)$ & 15.0 & \\
\hline & 1 adult, $\geq 1$ children & $155(7.5)$ & $27(11.2)$ & 17.4 & \\
\hline & 2 adults, $\geq 1$ children & $672(32.7)$ & $64(26.6)$ & 9.5 & \\
\hline & $\geq 3$ adults, $\geq 1$ children & $187(9.1)$ & $30(12.4)$ & 16.0 & \\
\hline \multirow[t]{4}{*}{ PCR test for SARS-CoV-2 } & Yes, positive result & $193(9.4)$ & $171(71.0)$ & 88.6 & \multirow[t]{4}{*}{$<0.001$} \\
\hline & Yes, negative result & $929(45.2)$ & $50(20.7)$ & 5.4 & \\
\hline & No & $932(45.3)$ & $20(8.3)$ & 2.1 & \\
\hline & Missing§ & $2(0.1)$ & - & - & \\
\hline
\end{tabular}


Table 1 (part 2 of 2): SARS-CoV-2 antibody seroprevalence by participant characteristics

\begin{tabular}{|c|c|c|c|c|c|}
\hline Characteristic & Category & $\begin{array}{c}\text { No. }(\%) \text { of } \\
\text { participants } \\
n=2056\end{array}$ & $\begin{array}{l}\text { No. }(\%) \text { of participants } \\
\text { with positive serology } \\
\qquad n=241\end{array}$ & Seroprevalence, \% & $p$ value \\
\hline \multirow{3}{*}{$\begin{array}{l}\text { COVID-19-congruent } \\
\text { symptoms }{ }^{\star \star}\end{array}$} & Yes & 768 (37.4) & $186(77.2)$ & 24.2 & \multirow{3}{*}{$<0.001$} \\
\hline & No & $1242(60.4)$ & $53(22.0)$ & 4.3 & \\
\hline & Missing§ & $46(2.2)$ & - & - & \\
\hline \multirow[t]{3}{*}{ Chronic disease } & Yes & $286(13.9)$ & $37(15.4)$ & 12.9 & \multirow[t]{3}{*}{0.5} \\
\hline & No & $1755(85.4)$ & $202(83.8)$ & 11.5 & \\
\hline & Missing§ & $15(0.7)$ & - & - & \\
\hline \multirow[t]{4}{*}{ Experience in the hospital } & Less than 1 year & $179(8.7)$ & $19(7.9)$ & 10.6 & \multirow[t]{4}{*}{0.4} \\
\hline & 1 to 4 year & $526(25.6)$ & $70(29.0)$ & 13.3 & \\
\hline & $\geq 5$ year & $1346(65.5)$ & $151(62.7)$ & 11.2 & \\
\hline & Missing§ & $5(0.2)$ & - & - & \\
\hline \multirow[t]{4}{*}{ Primary work shift } & Day & $1330(64.7)$ & $159(66.0)$ & 12.0 & \multirow[t]{4}{*}{0.3} \\
\hline & Evening & $417(20.3)$ & $54(22.4)$ & 12.9 & \\
\hline & Night & $289(14.1)$ & $27(11.2)$ & 9.3 & \\
\hline & Missing§ & $20(1.0)$ & - & - & \\
\hline \multirow{3}{*}{$\begin{array}{l}\text { Mean weekly number of } \\
\text { workdays }\end{array}$} & $\leq 2$ & $87(4.2)$ & $5(2.1)$ & 5.7 & \multirow[t]{3}{*}{0.09} \\
\hline & $\geq 3$ & $1958(95.2)$ & $235(97.5)$ & 12.0 & \\
\hline & Missing§ & $11(0.5)$ & - & - & \\
\hline \multirow{3}{*}{$\begin{array}{l}\text { Mean weekly number of } \\
\text { workdays in a hot zonet† }\end{array}$} & $\leq 2$ & $743(36.1)$ & $60(24.9)$ & 8.1 & \multirow[t]{3}{*}{$<0.001$} \\
\hline & $\geq 3$ & $1233(60.0)$ & $173(71.8)$ & 14.0 & \\
\hline & Missing§ & $80(3.9)$ & - & - & \\
\hline \multirow[t]{4}{*}{ Work at another site } & Yes, including long-term care & $100(4.9)$ & $16(6.6)$ & 16.0 & \multirow[t]{4}{*}{0.3} \\
\hline & Yes, no long-term care & $194(9.4)$ & $19(7.9)$ & 9.8 & \\
\hline & No & $1757(85.5)$ & $204(84.6)$ & 11.6 & \\
\hline & Missing§ & $5(0.2)$ & - & - & \\
\hline \multirow{6}{*}{$\begin{array}{l}\text { Worked in a unit affected by } \\
\text { a COVID-19 outbreak }\end{array}$} & Never & $742(36.1)$ & $36(14.9)$ & 4.9 & \multirow[t]{6}{*}{$<0.001$} \\
\hline & Rarely & $223(10.8)$ & $29(12.0)$ & 13.0 & \\
\hline & Sometimes & $281(13.7)$ & $39(16.2)$ & 13.9 & \\
\hline & Regularly & $561(27.3)$ & $114(47.3)$ & 20.3 & \\
\hline & Do not know & $245(11.9)$ & $22(9.1)$ & 10.0 & \\
\hline & Missing§ & $4(0.2)$ & - & - & \\
\hline \multirow{5}{*}{$\begin{array}{l}\text { Removal from work } \\
\text { because of a close contact } \\
\text { with a COVID-19 case }\end{array}$} & Yes, family contact & $44(2.1)$ & $12(5.0)$ & 27.3 & \multirow[t]{5}{*}{$<0.001$} \\
\hline & Yes, work contactł‡ & $212(10.3)$ & $81(33.6)$ & 38.2 & \\
\hline & Yes, other contact & $29(1.4)$ & $3(1.2)$ & 10.3 & \\
\hline & No & $1751(85.2)$ & $138(57.3)$ & 7.9 & \\
\hline & Missing§ & $20(1.0)$ & - & - & \\
\hline \multicolumn{6}{|c|}{ 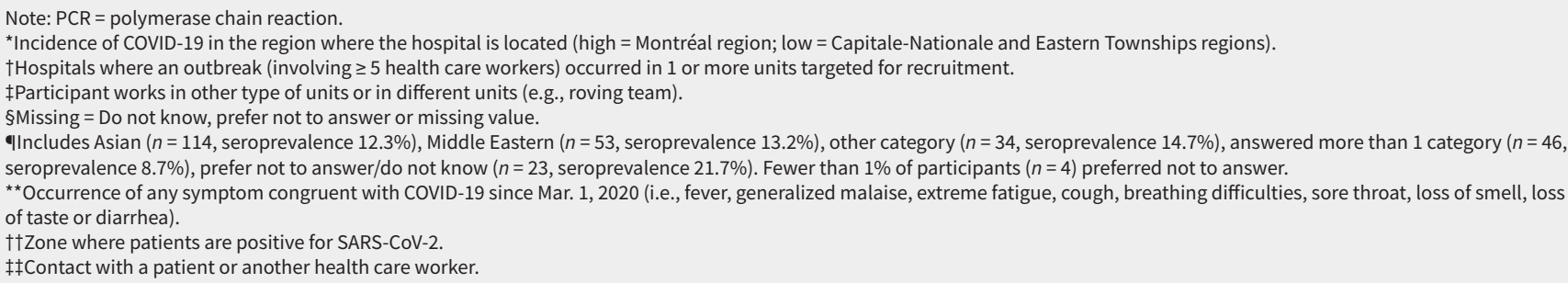 } \\
\hline
\end{tabular}




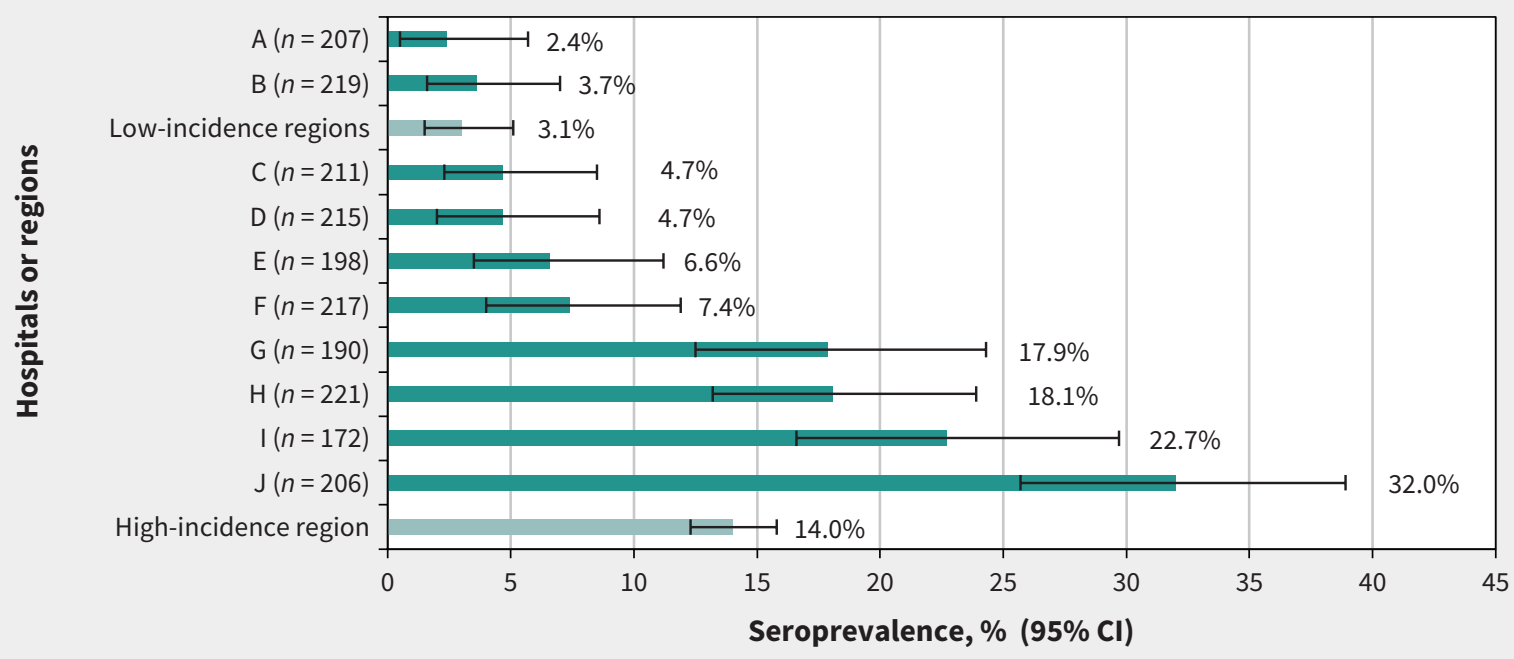

Figure 3: Seroprevalence by hospital (A-J) and type of region. Note: $\mathrm{Cl}=$ confidence interval. Each letter corresponds to a specific hospital. Hospitals $\mathrm{A}$ and $B$ are located in regions with low incidence of COVID-19 during the first wave of the pandemic (i.e., Capitale-Nationale and Eastern Townships). Hospitals $\mathrm{C}$ through $\mathrm{J}$ are located in the Montréal region, which had a high incidence of COVID-19 during the first wave.

Seroprevalence was higher in health care workers who mainly worked in inpatient COVID-19 units and non-COVID-19 units than in those who mainly worked in the emergency department or intensive care unit (Table 2). Seroprevalence was strongly associated with the presence or absence of outbreaks in inpatient COVID-19 and nonCOVID-19 units. In the 4 hospitals where outbreaks occurred, the mean seroprevalence was $33.4 \%$ among workers in inpatient units.

\section{Factors associated with seropositivity}

Factors associated with seropositivity in unadjusted analyses included regional incidence of COVID-19, working in a hospital where outbreaks occurred, main work unit, occupation and ethnicity (Table 1$)$. Age $(p=0.6)$ and sex $(p=0.3)$ did not show a statistically significant association with seropositivity.

In multivariable models (Table 3), compared with participants who mainly worked in an inpatient non-COVID-19 unit, seropositivity was lower among those who worked in the emergency department (adjusted prevalence ratio $0.61,95 \% \mathrm{Cl} 0.39-0.98$ ) or intensive care unit (adjusted prevalence ratio $0.47,95 \% \mathrm{Cl} 0.30-0.71$ ); seropositivity was numerically, but not significantly, higher in those working in an inpatient COVID-19 unit (adjusted prevalence ratio 1.48, 95\% Cl 0.932.36). Being a nurse or nursing assistant (adjusted prevalence ratio $1.34,95 \% \mathrm{Cl} 1.03-1.74$ ) or orderly (adjusted prevalence ratio 1.49, $95 \% \mathrm{Cl} 1.12-1.97$ ) was significantly associated with seropositivity compared with physicians, but being a member of the cleaning staff was not (adjusted prevalence ratio $0.88,95 \% \mathrm{Cl} 0.50-1.54$ ). Black or Hispanic ethnicity was also associated with seropositivity compared with being white (adjusted prevalence ratio 1.41, 95\% Cl 1.13-1.76). Finally, working in a hospital where an outbreak involving 5 or more health care workers occurred in 1 or more units targeted for recruitment was strongly associated with higher seropositivity (adjusted prevalence ratio $4.16,95 \% \mathrm{Cl} 2.63-6.57$ ).

\section{Laboratory results}

Among the 193 participants who reported a PCR-confirmed diagnosis of SARS-CoV-2 infection before blood sampling, 171 (88.6\%) had positive serology and $172(89.1 \%)$ reported having had symptoms of COVID-19. Of all 2056 participants, 171 (8.3\%) reported a PCRconfirmed diagnosis and had positive serology, 22 (1.1\%) had negative serology despite a PCR-confirmed diagnosis, and 70 (3.4\%) had positive serology in the absence of a PCR-confirmed diagnosis of SARSCoV-2 infection. Among the latter, 32 (45.7\%) had had COVID-19 symptoms. Among the 1791 participants with negative serology and without a COVID-19 diagnosis a lower percentage (32.2\%) reported having had symptoms. Overall, 171 (71\%) of 241 participants with positive serology reported a PCR-confirmed diagnosis of SARS-CoV-2 infection.

Of the 193 participants who reported a PCR-confirmed diagnosis, a positive PCR test result was found from the provincial database for 190 (98.4\%). Results using the anti-S1-receptor binding domain IgG/IgM assay produced only minor changes in seroprevalence estimates, compared with the main results (Appendix 1, Supplementary Results).

\section{Interpretation}

We observed a higher seroprevalence of SARS-CoV-2 infection among health care workers from 8 Montréal hospitals than among those from 2 hospitals in low-incidence regions of Quebec. The seroprevalence observed in this population in Montréal was similar to that in regions severely affected by the pandemic in Europe,,$^{11,13,16-18}$ but was lower than in the epicentres of the pandemic in London and New York..$^{19-21}$ The seroprevalence in Montréal hospitals was strongly influenced by outbreaks in both COVID-19 and non-COVID-19 inpatient units; the overall seroprevalence among health care workers in these hospitals was much higher than in 4 other Montréal hospitals that were less 
Table 2: SARS-CoV-2 antibody seroprevalence by hospital and main work unit

\begin{tabular}{|c|c|c|c|c|c|c|c|c|c|c|}
\hline \multirow[b]{2}{*}{ Hospital } & \multicolumn{2}{|c|}{$\begin{array}{c}\text { Emergency } \\
\text { department } \\
n=580\end{array}$} & \multicolumn{2}{|c|}{$\begin{array}{l}\text { Intensive care unit } \\
\qquad n=469\end{array}$} & \multicolumn{2}{|c|}{$\begin{array}{l}\text { COVID-19 unit } \\
n=436\end{array}$} & \multicolumn{2}{|c|}{$\begin{array}{l}\text { Non-COVID-10 unit } \\
n=438\end{array}$} & \multicolumn{2}{|c|}{$\begin{array}{l}\text { Other* } \\
n=133\end{array}$} \\
\hline & $\begin{array}{l}\text { No. of } \\
\text { HCWs }\end{array}$ & $\begin{array}{l}\text { No. (\%) with } \\
\text { positive } \\
\text { serology }\end{array}$ & $\begin{array}{l}\text { No. of } \\
\text { HCWs }\end{array}$ & $\begin{array}{l}\text { No. (\%) with } \\
\text { positive } \\
\text { serology }\end{array}$ & $\begin{array}{l}\text { No. of } \\
\text { HCWs }\end{array}$ & $\begin{array}{l}\text { No. (\%) with } \\
\text { positive } \\
\text { serology }\end{array}$ & $\begin{array}{l}\text { No. of } \\
\text { HCWs }\end{array}$ & $\begin{array}{l}\text { No. (\%) with } \\
\text { positive } \\
\text { serology }\end{array}$ & $\begin{array}{l}\text { No. of } \\
\text { HCWs }\end{array}$ & $\begin{array}{c}\text { No. }(\%) \text { with } \\
\text { positive } \\
\text { serology }\end{array}$ \\
\hline A, $n=207$ & 50 & $1(2.0)$ & 45 & $2(4.4)$ & 41 & $2(4.9)$ & 46 & $0(0.0)$ & 25 & $0(0.0)$ \\
\hline B, $n=219$ & 61 & $2(3.3)$ & 40 & $1(2.5)$ & 52 & $4(7.7)$ & 41 & $1(2.4)$ & 25 & $0(0.0)$ \\
\hline $\begin{array}{l}\text { Low-incidence } \\
\text { regions, } \dagger \\
n=426\end{array}$ & 111 & $3(2.7)$ & 85 & $3(3.5)$ & 93 & $6(6.4)$ & 87 & $1(1.2)$ & 50 & $0(0.0)$ \\
\hline$C, n=211$ & 50 & $2(4.0)$ & 52 & $0(0.0)$ & 42 & $2(4.8)$ & 62 & $6(9.7)$ & 5 & $0(0.0)$ \\
\hline D, $n=215$ & 60 & $0(0.0)$ & 55 & $2(3.6)$ & 28 & $3(10.7)$ & 62 & $4(6.4)$ & 10 & $1(10.0)$ \\
\hline$E, n=198$ & 84 & $6(7.2)$ & 40 & $0(0.0)$ & 28 & $4(14.3)$ & 37 & $1(2.7)$ & 10 & $2(20.0)$ \\
\hline$F, n=217$ & 57 & $6(10.5)$ & 60 & $1(1.7)$ & 43 & $5(11.6)$ & 42 & $3(7.1)$ & 15 & $1(6.7)$ \\
\hline $\mathrm{G}, n=190$ & 55 & $7(12.7)$ & 33 & $2(6.1)$ & 65 & $13(20.0)$ & 23 & $8(34.8)$ & 14 & $4(28.6)$ \\
\hline $\mathrm{H}, n=221$ & 52 & $7(13.5)$ & 61 & $4(6.6)$ & 50 & $26(52.0)$ & 48 & $2(4.2)$ & 10 & $1(10.0)$ \\
\hline I, $n=172$ & 61 & $9(14.8)$ & 28 & $2(7.1)$ & 39 & 15 (38.5) & 27 & $8(29.6)$ & 17 & $5(29.4)$ \\
\hline $\mathrm{J}, n=206$ & 51 & $6(11.8)$ & 55 & $15(27.3)$ & 48 & $27(56.2)$ & 50 & $18(36.0)$ & 2 & $0(0.0)$ \\
\hline $\begin{array}{l}\text { High-incidence } \\
\text { region, } \dagger \\
n=1630\end{array}$ & 469 & $43(9.2)$ & 384 & $26(6.8)$ & 343 & $95(27.7)$ & 351 & $50(14.2)$ & 83 & $14(16.9)$ \\
\hline
\end{tabular}

affected by outbreaks. The seroprevalence in these latter hospitals was higher than in the Montréal community $(<4 \%) .{ }^{5}$ These findings highlight the elevated risk of infection for health care workers in hospitals, particularly for those working in outbreak settings. Interestingly, the 4 Montréal hospitals with higher seroprevalence were older hospitals, a factor that has been associated with larger outbreaks. ${ }^{22}$

Other authors have identified lower seropositivity rates in intensive care units, ${ }^{16,17}$ which might be explained by the strict infection control measures implemented in these units, including personal protective equipment, and reduced staff mobility. Higher seropositivity rates in inpatient units ${ }^{23}$ have also been reported in previous seroprevalence studies. ${ }^{9,10,13,20}$ Several factors may explain this, including a physical environment that favours transmission, particularly in older hospitals (e.g., exiguity of the premises and indoor ventilation), suboptimal compliance with infection control measures, or presence of contagious patients (for COVID-9 units). In contrast, other studies have not found an increased risk in these units. ${ }^{11,12}$ In our study, some hospitals in Montréal had a seroprevalence among health care workers similar to that of the community and did not identify any outbreaks among health care workers in targeted care units.

Being a nurse $\mathrm{e}^{24,25}$ or orderly ${ }^{9,10}$ was independently associated with higher seropositivity rates in several other studies. An epidemiological investigation in Quebec also showed that most confirmed cases of COVID-19 in health care workers were among nurses or orderlies, who frequently acquired SARS-CoV-2 in the workplace. ${ }^{1}$ More frequent and close contact with patients could partly explain this association. ${ }^{10}$ Black or Hispanic ethnicity was also associated with higher seropositivity in multivariable analysis. Higher seropositivity in these populations has been found in seroprevalence studies in the United Kingdom and the US. ${ }^{10,13,19,21,24}$ The factors underlying this association are complex, ${ }^{26}$ unrelated to biological or genetic factors, ${ }^{27}$ and may reflect a higher seroprevalence in the community or several social factors, such as high population density, housing issues and people's ability to self-isolate outside of work. More research in the Canadian context is needed to understand the determinants of higher rates of SARS-CoV-2 seroprevalence among Black and Hispanic health care workers. ${ }^{28}$

In our study, most health care workers with IgG antibodies to SARS-CoV-2 had previously had a PCR-confirmed SARS-CoV-2 infection. Although the total number of participants with SARS-CoV-2 antibodies was about 25\% higher than the number with a COVID-19 diagnosis, our data attest to good case identification in Quebec hospitals. International seroprevalence studies have shown the number of people with a positive serology to be as much as twofold higher than those with PCR-confirmed SARS-CoV-2 infection. ${ }^{11,17}$ Moreover, the elevated sensitivity of the S1/S2 assay after a COVID19 diagnosis should be emphasized. Our results are consistent with study findings $\mathrm{s}^{29-32}$ that describe the stability of concentrations of the anti-spike antibody for at least 6 months. More work is needed to fully understand the duration of humoral immunity and the sensitivity of various serological assays over time..$^{33,34}$ 
Seroprevalence

No. (\%) with positive

Variable

No. of HCWs

Main work unit

Intensive care unit

Emergency department

Non-COVID-19 unit

COVID-19 unit

Other*

Occupation

Physician

Nurse or nursing assistant

Orderly

Cleaning staff

Ethnicity

White

Black $\uparrow$

Hispanic

Other‡,§

Work in a hospital where outbreaks occurredø

Yes

No

Mean weekly number of workdays

$\leq 2$

$\geq 3$

Mean weekly number of workdays in a hot zone $e^{\star \star}$

$\leq 2$

$\geq 3$

Household

No children

1 adult, $\geq 1$ children

2 adults, $\geq 1$ children

$\geq 3$ adults, $\geq 1$ children
469

580

438

436

133

432

1321

201

102

1594

140

52

270

789

1267

87

1958

743

1233

1042

155

672

187 serology

Crude $(95 \% \mathrm{Cl})$

Prevalence ratio

Note: $\mathrm{Cl}=$ confidence interval, $\mathrm{HCW}=$ health care workers, Ref. = reference category.

*Participant works in other type of units or in different units (e.g., roving team).

tMerged categories for Black and Hispanic participants for adjusted models because the model failed to converge when they were entered separately.

Includes Asian ( $n=114$, seroprevalence 12.3\%), Middle Eastern ( $n=53$, seroprevalence 13.2\%), other category $(n=34$, seroprevalence $14.7 \%)$, answered more than 1 category ( $n=46$, seroprevalence $8.7 \%)$, prefer not to answer/do not know $(n=23$, seroprevalence $21.7 \%)$. Fewer than $1 \%$ of participants $(n=4)$ preferred not to answer.

$\S$ Conclusions are the same if participants who answered "do not know" or "prefer not to answer" are excluded.

IHospitals where an outbreak (involving $\geq 5$ health care workers) occurred in 1 or more units targeted for recruitment.

${ }^{\star \star}$ Zone where patients are positive for SARS-CoV-2.

\section{Limitations}

We were unable to determine how SARS-CoV-2 was acquired by health care workers in our study (e.g., community acquisition, workplace acquisition). The $50 \%$ participation rate may imply the presence of selection bias. Reassuringly, particularly for groups with a lower participation rate (e.g., nurses and orderlies), we were able to compare the proportion with a previous

$\begin{array}{ccc}29(6.2) & 0.53(0.32-0.89) & 0.47(0.30-0.71) \\ 46(7.9) & 0.68(0.41-1.14) & 0.61(0.39-0.98) \\ 51(11.6) & \text { Ref. } & \text { Ref. } \\ 101(23.2) & 1.99(1.16-3.41) & 1.48(0.93-2.36) \\ 14(10.5) & 0.90(0.44-1.85) & 1.03(0.70-1.50)\end{array}$

$31(7.2)$

Ref.

Ref.

$163(12.3)$

$1.72(1.23-2.41)$

1.34 (1.03-1.74)

$36(17.9)$

$2.50(1.75-3.55)$

$1.49(1.12-1.97)$

$11(10.8)$

$1.50(0.78-2.89)$

$0.88(0.50-1.54)$

$163(10.2)$

Ref.

Ref.

$31(22.1)$

$2.17(1.42-3.29)$

$2.63(1.67-4.15)$

$1.41(1.13-1.76)$

$33(12.2)$

$1.20(0.77-1.87)$

$0.89(0.67-1.18)$

179 (22.7)

$62(4.9)$

4.64 (3.19-6.75)

Ref.

$4.16(2.63-6.57)$

Ref.

Ref.

Ref.

$235(12.0)$

$2.09(0.78-5.57)$

$1.75(0.67-4.58)$

Ref.

Ref.

$1.07(0.74-1.56)$

Ref.

Ref.

$1.51(0.88-2.59)$

1.22 (0.79-1.89)

$0.83(0.59-1.16)$

$0.83(0.61-1.12)$

$30(16.0)$

1.39 (1.02-1.91)

$1.02(0.76-1.38)$ 
The seroprevalence reported in each hospital may not reflect the exact seroprevalence among health care workers, as we targeted only a few specific units. However, the inclusion of 8 Montréal hospitals that collected data in a similar way provides a representative portrait of seroprevalence for each targeted type of unit in this region. External validity of our findings beyond urban regions of Quebec is limited and additional seroprevalence studies are required. Finally, the imperfect sensitivity and specificity of the S1/S2 assay could slightly underestimate or overestimate seroprevalence. This misclassification is likely nondifferential and might bias some study estimators toward the null hypothesis.

\section{Conclusion}

This study showed a high SARS-CoV-2 seroprevalence during the first wave of the COVID-19 pandemic. In 8 Montréal hospitals, the seroprevalence among health care workers was $14 \%$, which is significantly higher than rates in 2 hospitals in regions less affected by the first wave of COVID-19. Seroprevalence was strongly associated with the occurrence of outbreaks in the inpatient units of 4 hospitals, highlighting the risk of infection among hospital workers, particularly in outbreak settings and among nurses, nursing assistants and orderlies in particular. Although we could not identify whether infections were acquired in the hospital or assess the effectiveness of infection prevention and control measures, the high seroprevalence in 4 older hospitals may indicate that factors related to the physical environment, including exiguity of the premises and indoor ventilation, should be considered for preventing SARS-CoV-2 outbreaks, as they make implementation of optimal infection prevention and control measures more challenging. More work is needed to understand the mechanisms of transmission among infected health care workers to, ultimately, implement optimal protective measures. The high risk of SARS-CoV-2 infection in hospital workers supports the prioritization of this group for SARS-CoV-2 vaccination in Canada and efforts made to achieve a very high vaccine uptake in this population.

\section{References}

1. De Serres G, Carazo S, Lorcy A, et al. Enquête épidémiologique sur les travailleurs de la santé atteints par la COVID-19 au printemps 2020. Québec: Institut national de santé publique du Québec; 2020:1-60.

2. Gosselin E, Brousseau N, Fortin E, et al. Rapport épidémiologique descriptif de la COVID-19 au Québec du 23 février au 11 juillet 2020. Québec: Institut national de santé publique du Québec; 2020:1-43.

3. Cheng MP, Papenburg J, Desjardins M, et al. Diagnostic testing for severe acute respiratory syndrome-related coronavirus 2: a narrative review. Ann Intern Med 2020;172:726-34

4. Cheng MP, Yansouni CP, Basta NE, et al. Serodiagnostics for severe acute respiratory syndrome-related coronavirus 2: a narrative review. Ann Intern Med 2020; 173:450-60.

5. Étude de séroprévalence des anti-SRAS-CoV-2 chez les donneurs de sang d'Héma-Québec, vers la fin de la première vague de COVID-19: Étude No. ET-20004, Projet COVID-20-02. Montreal: Héma-Québec; 2021. Available: https:// www.hema-quebec.qc.ca/userfiles/file/coronavirus/COVID-20-02-rappot-final -20-02-2021.pdf (accessed 2021 Oct. 16).

6. Kumar D, Ferreira VH, Chruscinski A, et al. Prospective observational study of screening asymptomatic healthcare workers for SARS-CoV-2 at a Canadian tertiary care center. medRxiv 2020 July 28. doi: 10.1101/2020.07.21.20159053.

7. Bardai G, Ouellet J, Engelhardt T, et al. Prevalence of SARS-CoV-2 infections in a pediatric orthopedic hospital. Paediatr Anaesth 2021;31:247-8.
8. Galanis P, Vraka I, Fragkou D, et al. Seroprevalence of SARS-CoV-2 antibodies and associated factors in health care workers: a systematic review and metaanalysis. medRxiv 2020 Oct. 28. doi: 10.1101/2020.10.23.20218289.

9. Rudberg A-S, Havervall S, Månberg A, et al. SARS-CoV-2 exposure, symptoms and seroprevalence in healthcare workers in Sweden. Nat Commun 2020;11:5064.

10. Cooper DJ, Lear S, Watson L, et al. A prospective study of risk factors associated with seroprevalence of SARS-CoV-2 antibodies in healthcare workers at a large UK teaching hospital medRxiv 2020 Nov. 4. doi: 10.1101/2020.11.03.20220699.

11. Garcia-Basteiro AL, Moncunill G, Tortajada M, et al. Seroprevalence of antibodies against SARS-CoV-2 among health care workers in a large Spanish reference hospital. Nat Commun 2020;11:3500.

12. Steensels D, Oris E, Coninx L, et al. Hospital-wide SARS-CoV-2 antibody screening in 3056 staff in a tertiary center in Belgium. JAMA 2020;324:195-7.

13. Eyre DW, Lumley SF, O'Donnell D, et al. Differential occupational risks to healthcare workers from SARS-CoV-2 observed during a prospective observational study. eLife 2020;9:e60675.

14. Therrien C, Serhir B, Bélanger-Collard M, et al. Multicenter evaluation of the clinical performance and the neutralizing antibody activity prediction properties of 10 high-throughput serological assays used in clinical laboratories. J Clin Microbiol 2021;59:e02511-20.

15. Betensky RA, Talcott JA, Weeks JC. Binary data with two, non-nested sources of clustering: an analysis of physician recommendations for early prostate cancer treatment. Biostatistics 2000;1:219-30.

16. Sandri MT, Azzolini E, Torri V, et al. IgG serology in health care and administrative staff populations from 7 hospital representative of different exposures to SARSCoV-2 in Lombardy, Italy. medRxiv 2020 May 26. doi: 10.1101/2020.05.24.20111245.

17. Barallat J, Fernández-Rivas G, Quirant-Sánchez B, et al. Seroprevalence of SARS-CoV-2 IgG specific antibodies among healthcare workers in the northern metropolitan area of Barcelona, Spain, after the first pandemic wave. PLoS One 2020;15:e0244348.

18. Abo-Leyah H, Gallant S, Cassidy D, et al. Seroprevalence of SARS-COV-2 antibodies in Scottish healthcare workers. medRxiv 2020 Oct. 2. doi: 10.1101/2020.10.02.20205641.

19. Venugopal U, Jilani N, Rabah S, et al. SARS-CoV-2 seroprevalence among health care workers in a New York City hospital: a cross-sectional analysis during the COVID-19 pandemic. Int J Infect Dis 2021;102:63-9.

20. Grant JJ, Wilmore SMS, McCann NS, et al. Seroprevalence of SARS-CoV-2 antibodies in healthcare workers at a London NHS trust. Infect Control Hosp Epidemiol 2021;42:212-4.

21. Shields A, Faustini SE, Perez-Toledo M, et al. SARS-CoV-2 seroprevalence and asymptomatic viral carriage in healthcare workers: a cross-sectional study. Thorax 2020;75:1089-94.

22. Stall NM, Jones A, Brown KA, et al. For-profit long-term care homes and the risk of COVID-19 outbreaks and resident deaths. CMAJ 2020;192:E946-55.

23. Lidström A-K, Sund F, Albinsson B, et al. Work at inpatient care units is associated with an increased risk of SARS-CoV-2 infection; a cross-sectional study of 8679 healthcare workers in Sweden. Ups J Med Sci 2020;125:305-10.

24. Akinbami LJ, Vuong N, Petersen LR, et al. SARS-CoV-2 seroprevalence among healthcare, first response, and public safety personnel, Detroit metropolitan area, Michigan, USA, May-June 2020. Emerg Infect Dis 2020;26:2863-71.

25. Jespersen S, Mikkelsen S, Greve T, et al. SARS-CoV-2 seroprevalence survey among 17,971 healthcare and administrative personnel at hospitals, pre-hospital services, and specialist practitioners in the central Denmark region. Clin Infect Dis 2020;73:e2853-60.

26. Phelan JC, Link BG. Is racism a fundamental cause of inequalities in health? Annu Rev Sociol 2015;41:311-30.

27. A conceptual framework for action on the social determinants of health. Geneva: World Health Organization; 2010:1-79.

28. Williamson EJ, Walker AJ, Bhaskaran K, et al. Factors associated with COVID19-related death using OpenSAFELY. Nature 2020;584:430-6.

29. Wu J, Liang B, Chen C, et al. SARS-CoV-2 infection induces sustained humoral immune responses in convalescent patients following symptomatic COVID-19. Nat Commun 2021;12:1813.

30. Ripperger TJ, Uhrlaub JL, Watanabe M, et al. Orthogonal SARS-CoV-2 serological assays enable surveillance of low-prevalence communities and reveal durable humoral immunity. Immunity 2020;53:925-33.e4.

31. Muecksch F, Wise H, Batchelor B, et al. Longitudinal serological analysis and neutralizing antibody levels in coronavirus disease 2019 convalescent patients. J Infect Dis 2021;223:389-98.

32. Dan JM, Mateus J, Kato Y, et al. Immunological memory to SARS-CoV-2 assessed for greater than six months after infection. bioRxiv 2020 Dec. 18. doi: 10.1101/ 2020.11.15.383323.

33. Kontou PI, Braliou GG, Dimou NL, et al. Antibody tests in detecting SARS-CoV-2 infection: a meta-analysis. Diagnostics (Basel) 2020;10:319.

34. Gudbjartsson DF, Norddahl GL, Melsted P, et al. Humoral immune response to SARS-CoV-2 in Iceland. N Engl J Med 2020;383:1724-34. 
Competing interests: Patrice Savard reports grants from Merck, Sunovion and Verity Pharmaceuticals. Yves Longtin reports grants from Merck, GenePOC, Becton Dickinson and Gojo. Matthew Cheng reports grants from the McGill Interdisciplinary Initiative in Infection and Immunity, Consortium Québécois sur la découverte du médicament and Canadian Institutes of Health Research; personal fees from GEn1E Lifesciences and nplexbio; 2 pending patents for methods related to using cell-free DNA; and participation with the Canadian Immunity Task Force. Jean-Michel Leduc reports research funding from Biomérieux. All reported competing interests were outside the submitted work. No other competing interests were declared.

This article has been peer reviewed.

Affiliations: Institut national de santé publique du Québec (Brousseau, Ouakki, De Serres), Montréal, Que.; Centre de recherche du CHU de QuébecUniversité Laval (Brousseau, Morin, De Serres), Québec, Que.; Départements de médecine et de médecine des laboratoires (Savard), Centre Hospitalier de l'Université de Montréal; Centre de recherche du Centre Hospitalier de l'Université de Montréal (Savard); Department of Microbiology, Infectious Diseases \& Immunology (Quach), CHU Sainte-Justine, Université de Montréal; Jewish General Hospital (Longtin); Divisions of Infectious Disease and Medical Microbiology (Cheng), McGill University Health Center, Montréal, Que.; CIUSSS de l'Estrie - CHUS (Carignan, Lévesque, Martin); Département de microbiologie et infectiologie (Carignan, Lévesque, Martin), Faculté de médecine et des sciences de la santé, Université de Sherbrooke, Sherbrooke, Que.; Département de médecine (Dufresne, Lavallée), CIUSSS-de-l'Est-de-l'île-de-Montréal; CIUSSS du Nord-de-l'île-de-Montréal (Leduc, Gauthier), Montréal, Que.; Hôpital de l'Enfant-Jésus du CHU de Québec (Bestman-Smith), Québec, Que.; CIUSSS de l'Ouest-de-l'île-de-Montréal (Arrieta); CIUSSS du Centre-Sud-de-l'île-de-Montréal (Ishak), Montréal, Que.

Contributors: Nicholas Brousseau and Gaston De Serres conceived the study. Patrice Savard, Caroline Quach, Yves Longtin, Matthew Cheng and Alex Carignan contributed to the study design. Laurianne Morin and
Manale Ouakki conducted the analyses. All of the authors contributed to data analysis and interpretation. Nicholas Brousseau wrote the first draft of the manuscript. All authors contributed to the drafting of the manuscript, critically revised the manuscript for important intellectual content, gave final approval of the version to be published and agreed to be accountable for all aspects of the work.

Content licence: This is an Open Access article distributed in accordance with the terms of the Creative Commons Attribution (CC BY-NC-ND 4.0) licence, which permits use, distribution and reproduction in any medium, provided that the original publication is properly cited, the use is noncommercial (i.e., research or educational use), and no modifications or adaptations are made. See: https://creativecommons.org/ licenses/by-nc-nd/4.0/

Funding: This work was supported by Quebec Ministry of Health and Social Services.

Data sharing: All or portions of the data are available to others. Data will be available upon publication and may be accessed by contacting the corresponding author.

Acknowledgements: The authors thank Sophie Auger, Stéphanie Beauchemin, Christina Benjamin, Christine Blaser, France Bouchard, Valérie Boucher, Mathieu Brodeur, Geneviève Cadieux, Sara Carazo, Annie Chamberland, Marie-Laure Dablaka, Anatolie Duca, Catherine Dupont, Jennifer Eastmond, Marcel Émond, Alvine Fansi, Nathalie Gravel, Sandrine Hegg-Deloye, Zineb Laghdir, Catherine Lambert, Nadine Larente, Gregory Léon, Sondra Mandy Sinanan, Dominique Marcoux, Pierre-Henri Minot, Naiana Muntini, Gentiane Perrault-Sullivan, Karène Proulx-Boucher, Josiane Rivard, Jonathan Roger, Molly Ann Rothschild, Nadine Sicard, Denis Talbot, Esther Trudel, Donald Vinh, Cédric Yansouni, Chung Yan Yuen, Daysi Zentner and the McGill University Health Centre COVID Biobank.

Accepted: Nov. 4, 2021

Correspondence to: Nicholas Brousseau, nicholas.brousseau@inspq.qc.ca 